\title{
Stereoselective synthesis of tetrasubstituted alkenes via a sequential carbocupration and a new sulfur-lithium exchange
}

\author{
Andreas Unsinn, Cora Dunst and Paul Knochel ${ }^{*}$
}

Letter
Address:
Department Chemie, Ludwig-Maximilians-Universität München,
Butenandtstr. 5-13, 81377 München, Germany
Email:
Paul Knochel ${ }^{*}$ - paul.knochel@cup.uni-muenchen.de
*Corresponding author
Keywords:
alkenes; carbometalation; copper; regioselectivity; stereoselectivity

Beilstein J. Org. Chem. 2012, 8, 2202-2206.
doi:10.3762/bjoc.8.248
Received: 17 October 2012
Accepted: 05 December 2012
Published: 18 December 2012
This article is part of the Thematic Series "Carbometallation chemistry".
Guest Editor: I. Marek
@ 2012 Unsinn et al; licensee Beilstein-Institut.
License and terms: see end of document.

\begin{abstract}
We have designed a new sequential carbocupration and sulfur-lithium exchange that leads stereo- and regioselectively to trisubstituted alkenyllithiums. Subsequent trapping with various electrophiles yields tetrasubstituted olefins with good control of the doublebond geometry ( $E / Z$ ratio up to 99:1). The novel sulfur-lithium exchange could be extended to the stereoselective preparation of $Z$-styryl lithium derivatives with almost complete retention of the double-bond geometry.
\end{abstract}

\section{Introduction}

The stereoselective synthesis of tetrasubstituted alkenes is an important synthetic goal, which may be achieved by carbometalation methods [1-9]. The Normant carbocupration of terminal acetylenes allows the stereoselective preparation of trisubstituted alkenes with excellent $E / Z$ ratio [10-12]. However, in order to obtain tetrasubstituted alkenes, a carbometalation of an internal alkene is required. This reaction is usually difficult due to steric hindrance and proceeds only if electron-withdrawing groups are attached to the alkyne unit to facilitate the carbometalation step. Recently, we studied the chemistry of alkenyl sulfides and their use for carbometalation extensively [13].

Therefore, we envisioned using an alkynyl thioether such as $\mathbf{1}$ as an activated alkyne. After a carbocupration of the alkynyl thioether 1 with the organozinc reagent 2 in the presence of $\mathrm{CuCN} \cdot 2 \mathrm{LiCl}$ [14], the alkenylcopper species 3 should be obtained. Stereoselective quenching with an electrophile $\left(\mathrm{E}^{1}\right)$ should afford the tetrasubstituted alkenyl thioether 4. Extensive experimentation showed that thioethers 4 do not undergo Ni- or Pd-catalyzed cross couplings leading to products of type $\mathbf{5}$ $(\mathrm{R}=\mathrm{Me}, \mathrm{Ph})[15,16]$. Thus, we designed a new sulfur-lithium exchange (Scheme 1).

Sulfur-lithium exchanges proceed only readily with sulfoxides [17-19] and these reactions are often complicated by radical side reactions [20,21]. This new, direct sulfur-lithium exchange on an alkenyl thioether of type 4 involves the use of a bromobiphenyl R-group, which by treatment with BuLi at low 


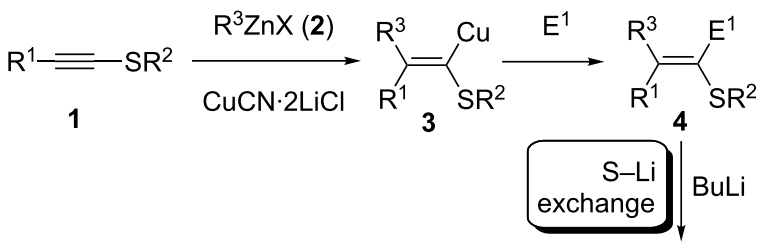

$$
\begin{aligned}
& \overbrace{R_{5}^{1}}^{R_{E^{2}}}<_{\mathrm{R}_{7}^{1}}^{\mathrm{E}^{1}} \underbrace{\mathrm{E}^{2}}_{\mathrm{Li}}
\end{aligned}
$$

Scheme 1: Synthesis of tetrasubstituted olefins by a successive carbocupration and S-Li exchange.

temperatures, undergoes first a fast bromine-lithium exchange leading to an intermediate biphenyllithium derivative of type $\mathbf{6}$, followed by an intramolecular ring-closing sulfur-lithium exchange [22] leading to the desired alkenyllithium 7 (Scheme 2).

Subsequent quenching with a different electrophile $\mathrm{E}^{2}$ should afford the tetrasubstituted alkene of type 5; (Scheme 1). Herein, we demonstrate the feasibility of this methodology and thus prepare tetrasubstituted alkenes with $E / Z$ stereoselectivities up to 99:1. Furthermore, we show that this sulfur-lithium exchange can be extended to the stereoselective preparation of $Z$-styryl derivatives.

\section{Results and Discussion}

First, we wish to report the synthesis of the alkynyl biphenyl thioether 1a required for the carbometalation step. Thus, octyne was deprotonated with butyllithium (1.1 equiv, THF, $-78^{\circ} \mathrm{C}$, $2 \mathrm{~h}$ ) followed by the addition of the diaryl disulfide [23] (8: 1.1 equiv, $-78^{\circ} \mathrm{C}$ to $25^{\circ} \mathrm{C}, 3 \mathrm{~h}$ ) providing the bromothioether 9 in $77 \%$ yield. Direct Pd-catalyzed Negishi cross-coupling [2428 ] of 9 with an arylzinc derivative failed. However, the bromide 9 could be readily converted to the corresponding iodide $\mathbf{1 0}$ by a bromine-magnesium exchange using iPrMgCl$\cdot \mathrm{LiCl}$ [29-35] followed by iodolysis leading to the iodide 10 in $93 \%$ yield. Treatment of 1,2-dibromobenzene with iPrMgCl$\cdot \mathrm{LiCl}$ at $-15{ }^{\circ} \mathrm{C}$ for $2 \mathrm{~h}$ followed by a transmetalation with $\mathrm{ZnCl}_{2}$ gives the required zinc reagent 11, which undergoes a Negishi cross-coupling with the iodide $\mathbf{1 0}$ at $50{ }^{\circ} \mathrm{C}(5 \mathrm{~h})$ leading to the alkynyl thioether $\mathbf{1 a}$ in $80 \%$ yield (Scheme 3 ).<smiles>[R]C([Z17])=C(Br)Sc1ccccc1-c1ccccc1Br</smiles>

4

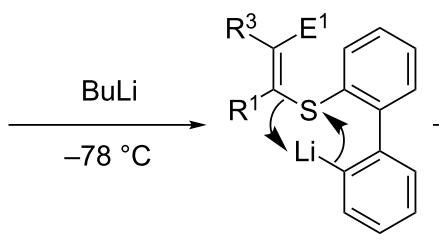

6<smiles>[R]/C([AlH])=C(/[R])[Tl]</smiles>

7

Scheme 2: Proposed mechanism of the sulfur-lithium exchange starting with the alkenyl thioether 4

$$
=\frac{\text { 1) } \mathrm{BuLi}, \mathrm{THF},}{-78^{\circ} \mathrm{C}, 2 \mathrm{~h}}
$$

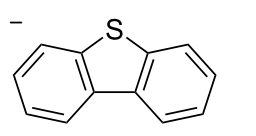

20 to $0{ }^{\circ} \mathrm{C}, 10 \mathrm{~h}$

2) $\mathrm{I}_{2}$

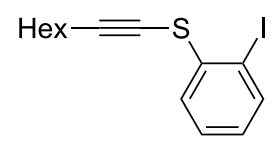

10: $93 \%$

11

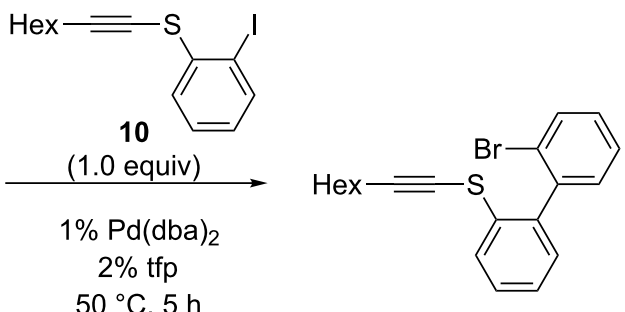

1a: $80 \%$ 
The harsh cross-coupling conditions may be due booth to the presence of the ortho-bromo substitution in the zinc reagent $\mathbf{1 1}$, which considerably reduces the nucleophilicity of this arylzinc reagent by inductive effects, and also to the sulfur atom of the electrophile, which poisons the Pd catalyst. With the thioether 1a in hand, we have performed the Normant carbocupration with di-para-anisylzinc $\left(\mathrm{An}_{2} \mathrm{Zn}\right.$ : 2a) according to a procedure previously developed by us [36]. Thus, the reaction of $\mathbf{1 a}$ (1.0 equiv) with $\mathrm{An}_{2} \mathrm{Zn}$ (1.5 equiv, THF) in the presence of $\mathrm{CuCN} \cdot 2 \mathrm{LiCl}\left(1.5\right.$ equiv) at $25^{\circ} \mathrm{C}$ for $8 \mathrm{~h}$ produces the intermediate copper reagent $\mathbf{3 a}$, which, after allylation with allyl bromide, provides the thioether $4 \mathbf{a}$ in $84 \%$ yield and an $E / Z$ ratio of 99:1 (Scheme 4). The reaction of $\mathbf{3 a}$ with other typical electrophiles is possible, but proceeds in moderate yields due to the low reactivity of copper reagent $\mathbf{3 a}$.

The bromothioether $\mathbf{4 a}$ was then treated with $s$-BuLi (1.3 equiv, $-78^{\circ} \mathrm{C}, 10 \mathrm{~min}$ ), leading to the formation of the intermediate aryllithium $\mathbf{6 a}$, which undergoes the desired intramolecular sulfur-lithium exchange affording the alkenyllithium reagent 7a (Scheme 5).

This alkenyllithium was quenched with typical electrophiles with a high retention of the double-bond geometry. Thus, the treatment of 7a with EtI ( 2 equiv, $-78{ }^{\circ} \mathrm{C}, 15 \mathrm{~min}$ ) provides the tetrasubstituted alkene 5a in $75 \%$ yield and an $E / Z$ ratio of 1:99. Direct carboxylation by the reaction with ethyl chloroformate
(1.1 equiv, $-78^{\circ} \mathrm{C}, 15 \mathrm{~min}$ ) furnishes the corresponding unsaturated ethylester $\mathbf{5 b}$ in $55 \%$ isolated yield and an $E / Z$ ratio of $95: 5$. Finally, a copper-catalyzed allylation with ethyl 2-(bromomethyl)acrylate [37] (1.5 equiv, -78 to $0{ }^{\circ} \mathrm{C}, 2 \mathrm{~h}$ ) affords the triene $5 \mathbf{c}$ in $55 \%$ yield and an $E / Z$ ratio of $99: 1$ (Scheme 6).

These quenching experiments demonstrate that this new method based on a successive carbocupration and sulfur-lithium exchange allows the stereoselective preparation of various tetrasubstituted alkenes. Since Normant has shown that various alkylcopper species add to alkynyl thioethers [38-40], the use of a bromobiphenyl substituent $\left(\mathrm{R}^{2}\right)$ on the sulfur may allow a general stereoselective synthesis of tetra-substituted alkenes.

In order to prove that this new sulfur-lithium exchange has further applications in the stereoselective synthesis of alkenes, we prepared the $Z$-alkenyl thioether 12 starting from 2,2'dibromobiphenyl. Thus, the performance of a double bromine-lithium exchange with $\mathrm{BuLi}$ (1.1 equiv, $-78^{\circ} \mathrm{C}$, $0.25 \mathrm{~h}$ ) followed by a quenching with tetramethylthiuram disulfide ( 1.1 equiv, -78 to $25^{\circ} \mathrm{C}, 12 \mathrm{~h}$ ) furnishes the dithiocarbamate 13 in $82 \%$ yield. Since the reduction to the free thiol is hard to achieve due to dibenzothiophene formation [41], we performed an in situ deprotection and stereoselective addition to phenylacetylene [42] (1.5 equiv, 1.25 equiv $\mathrm{NaOEt}$, EtOH,

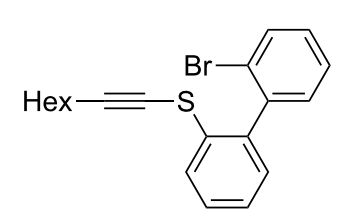

$1 a$

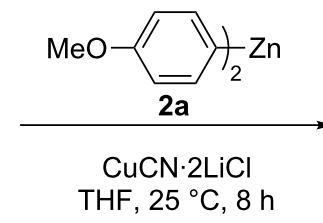

$\mathrm{THF}, 25^{\circ} \mathrm{C}, 8 \mathrm{~h}$

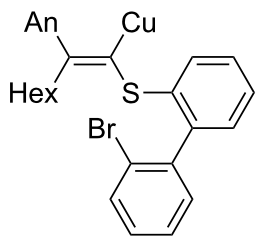

$3 \mathbf{a}$

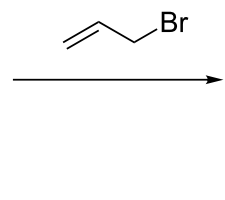

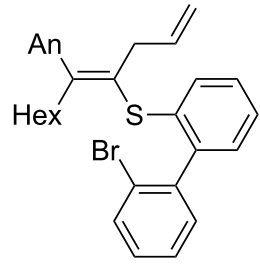

4a: $84 \%$

99:1 E/Z

Scheme 4: Carbocupration of the thioether 1a leading to the tetrasubstituted alkene 4a.

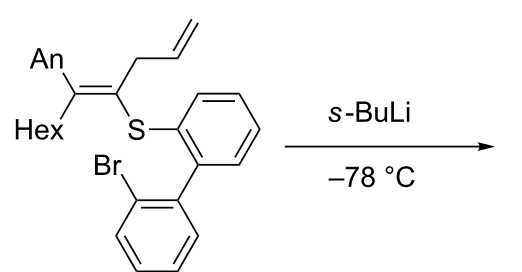

$4 a$

$99: 1 E / Z$

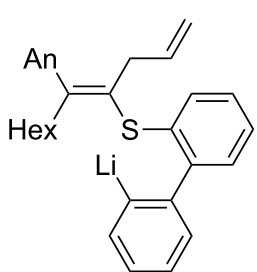

$6 a$

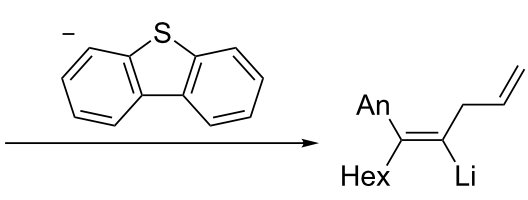

$7 \mathbf{a}$

99:1 E/Z 

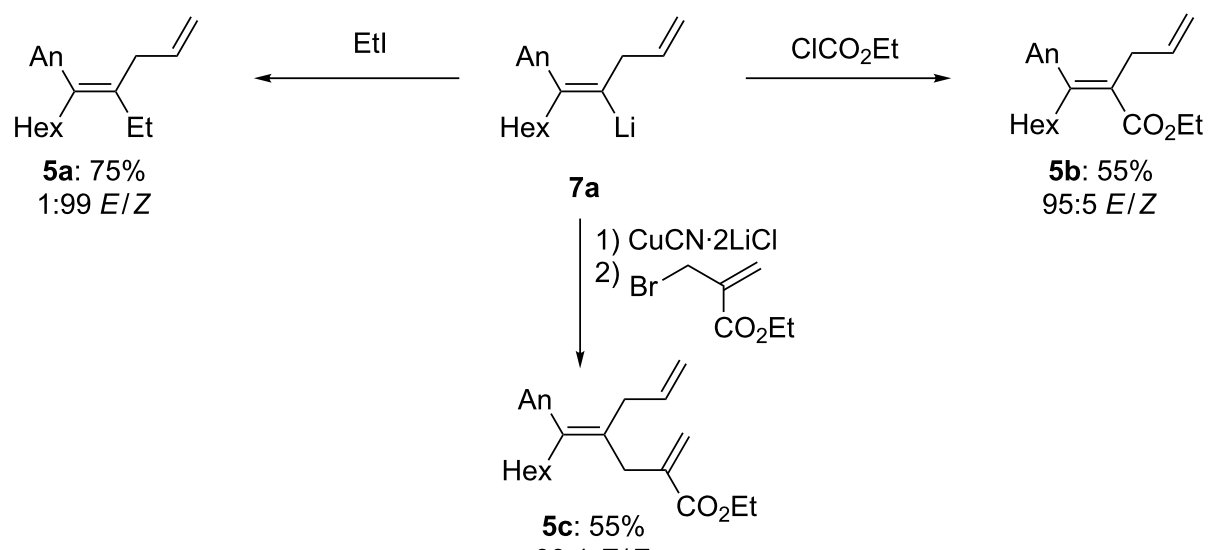

$99: 1 E / Z$

Scheme 6: Quenching of the alkynyllithium 7a. (Product ratios and diastereoselectivities were determined by ${ }^{1} \mathrm{H}-$ and $2 \mathrm{D}-\mathrm{NMR}$.)

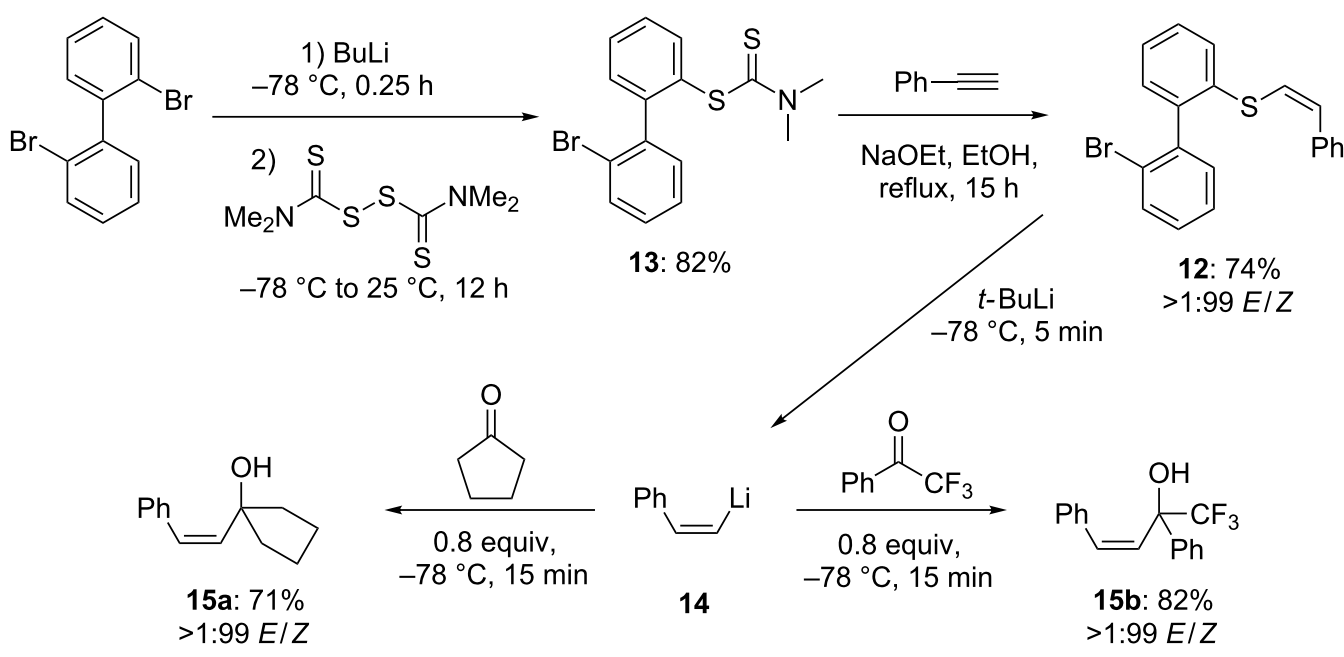

Scheme 7: Synthesis and quenching of Z-styryllithium.

reflux, $15 \mathrm{~h}$ ) yielding the $Z$-alkenyl thioether 12 in $74 \%$ yield (Scheme 7).

Treatment of 12 with $t$-BuLi (1.6 equiv, $-78^{\circ} \mathrm{C}, 10 \mathrm{~min}$ ) provides directly the $Z$-styryllithium 14 , which stereoselectively adds to $\alpha, \alpha, \alpha$-trifluoroacetophenone ( 0.8 equiv, $-78^{\circ} \mathrm{C}$, $0.5 \mathrm{~h})$ and cyclopentanone ( 0.8 equiv, $\left.-78{ }^{\circ} \mathrm{C}, 0.5 \mathrm{~h}\right)$ to afford the expected tertiary allylic alcohols $\mathbf{1 5 a}-\mathbf{b}$ in $71-82 \%$ yield and $E / Z$ ratios of $>1: 99$.

\section{Conclusion}

In summary, we have reported tetrasubstituted olefins with excellent $E / Z$ ratios using a sequential carbocupration and a new sulfur-lithium exchange involving an alkenyl thioether bearing a 2'-bromobiphenyl substituent, which triggers efficiently the sulfur-lithium exchange. Extension to the stereoselective preparation of Z-styryllithium was shown.

\section{Supporting Information}

\section{Supporting Information File 1}

Experimental details and characterization data of new compounds.

[http://www.beilstein-journals.org/bjoc/content/ supplementary/1860-5397-8-248-S1.pdf]

\section{Acknowledgements}

We thank the Fonds der Chemischen Industrie and the European Research Council (ERC) for financial support. We also 
thank BASF SE (Ludwigshafen), Heraeus Holding GmbH (Hanau) and Rockwood Lithium GmbH (Frankfurt) for the generous donation of chemicals.

\section{References}

1. Itami, K.; Kamei, T.; Yoshida, J. J. Am. Chem. Soc. 2003, 125, 14670. doi:10.1021/ja037566i

2. Das, J. P.; Chechik, H.; Marek, I. Nat. Chem. 2009, 1, 128. doi:10.1038/nchem.131

3. Zhou, C.; Larock, R. C. Org. Lett. 2005, 7, 259. doi:10.1021/ol047759q

4. Alonso, F.; Beletskaya, I. P.; Yus, M. Chem. Rev. 2004, 104, 3079. doi:10.1021/cr0201068

5. Shirakawa, E.; Ikeda, D.; Masui, S.; Yoshida, M.; Hayashi, T. J. Am. Chem. Soc. 2012, 134, 272. doi:10.1021/ja206745w

6. Dutta, B.; Gilboa, N.; Marek, I. J. Am. Chem. Soc. 2010, 132, 5588. doi:10.1021/ja101371x

7. Flynn, A. B.; Ogilvie, W. W. Chem. Rev. 2007, 107, 4698. doi:10.1021/cr050051k

8. Basheer, A.; Marek, I. Beilstein J. Org. Chem. 2010, 6, No. 77. doi:10.3762/bjoc.6.77

9. Achyutha Rao, S.; Knochel, P. J. Am. Chem. Soc. 1991, 113, 5735. doi:10.1021/ja00015a030

10. Normant, J. F.; Bourgain, M. Tetrahedron Lett. 1971, 12, 2583. doi:10.1016/S0040-4039(01)96925-4

11. Normant, J. F.; Alexakis, A. Synthesis 1981, 841. doi:10.1055/s-1981-29622

12. Knochel, P. Carbometallation of Alkenes and Alkynes. In Comprehensive Organic Syntheses: Selectivity, Strategy and Efficiency. In Modern Organic Chemistry; Trost, B. M.; Fleming, I.; Semmelhack, M. F., Eds.; Pergamon Press: Oxford, U.K., 1992; Vol. 4, pp 865-911.

13. Dunst, C. Functionalization of Arenes and Heteroarenes by Metalation with TMP-Bases or Metal Insertion and Synthesis of Tetrasubstituted Alkenyl Sulfides via a Cu(I)-Mediated Carbometalation. Ph.D. Thesis, Ludwig-Maximilians-Universität München, Munich, Germany, 2011.

14. Knochel, P.; Yeh, M. C. P.; Berk, S. C.; Talbert, J. J. Org. Chem. 1988, 53, 2390. doi:10.1021/jo00245a057

15. Metzger, A.; Melzig, L.; Despotopoulou, C.; Knochel, P. Org. Lett. 2009, 11, 4228. doi:10.1021/ol9017003

16. Melzig, L.; Metzger, A.; Knochel, P. J. Org. Chem. 2010, 75, 2131. doi:10.1021/jo1001615

17. Satoh, T.; Takano, K.; Someya, H.; Matsuda, K. Tetrahedron Lett. 1995, 36, 7097. doi:10.1016/0040-4039(95)01435-K

18. Satoh, T.; Takano, K.; Ota, H.; Someya, H.; Matsuda, K.; Koyama, M. Tetrahedron 1998, 54, 5557. doi:10.1016/S0040-4020(98)00243-9

19. Satoh, T. Chem. Soc. Rev. 2007, 36, 1561. doi:10.1039/b615630b

20. Rauhut, C. B.; Melzig, L.; Knochel, P. Org. Lett. 2008, 10, 3891. doi:10.1021/ol801431z

21. Melzig, L.; Rauhut, C. B.; Knochel, P. Chem. Commun. 2009, 3536. doi:10.1039/b907330b

22. Stoll, A. H.; Krasovskiy, A.; Knochel, P. Angew. Chem. 2006, 118, 621. doi:10.1002/ange.200501882

Angew. Chem. Int. Ed. 2006, 45, 606. doi:10.1002/anie.200501882

23. Korn, T. J.; Knochel, P. Synlett 2005, 1185. doi:10.1055/s-2005-865230

24. Negishi, E.; King, A. O.; Okukado, N. J. Org. Chem. 1977, 42, 1821. doi:10.1021/jo00430a041

25. Negishi, E.; Okukado, N.; King, A. O.; Van Horn, D. E.; Spiegel, B. I. J. Am. Chem. Soc. 1978, 100, 2254. doi:10.1021/ja00475a059
26. Negishi, E.; Takahashi, T.; Baba, S.; Van Horn, D. E.; Okukado, N. J. Am. Chem. Soc. 1987, 109, 2393. doi:10.1021/ja00242a024

27. Negishi, E. Acc. Chem. Res. 1982, 15, 340. doi:10.1021/ar00083a001

28. Negishi, E. Angew. Chem. 2011, 123, 6870.

doi:10.1002/ange.201101380

Angew. Chem., Int. Ed. 2011, 50, 6738. doi:10.1002/anie.201101380

29. Krasovskiy, A.; Knochel, P. Angew. Chem. 2004, 116, 3396. doi:10.1002/ange.200454084

Angew. Chem., Int. Ed. 2004, 43, 3333. doi:10.1002/anie.200454084

30. Sämann, C.; Haag, B.; Knochel, P. Chem.-Eur. J. 2012, 18, 16145. doi:10.1002/chem.201202230

31. Rauhut, C. B.; Knochel, P.; Vu, V. A.; Fleming, F. F. Org. Lett. 2008, 10, 1187. doi:10.1021/ol8000987

32. Shi, L.; Chu, Y.; Knochel, P.; Mayr, H. Angew. Chem. 2008, 120, 208. doi:10.1002/ange. 200704100

Angew. Chem. Int. Ed. 2008, 47, 202; doi:10.1002/anie.200704100

33. Kopp, F.; Knochel, P. Org. Lett. 2007, 9, 1639. doi:10.1021/ol063136w

34. Kopp, F.; Wunderlich, S.; Knochel, P. Chem. Commun. 2007, 2075. doi:10.1039/b618923g

35. Ila, H.; Baron, O.; Wagner, A. J.; Knochel, P. Chem. Lett. 2006, 35, 2. doi:10.1246/cl.2006.2

36. Dunst, C.; Metzger, A.; Zaburdaeva, E. A.; Knochel, P. Synthesis 2011, 3453. doi:10.1055/s-0030-1260210

37. Villieras, J.; Rambaud, M. Synthesis 1982, 924. doi:10.1055/s-1982-29998

38. Masure, D.; Coutrot, P.; Normant, J. F. J. Organomet. Chem. 1982, 226, C55. doi:10.1016/S0022-328X(00)83415-4

39. Alexakis, A.; Cahiez, G.; Normant, J. F. Tetrahedron 1980, 36, 1961. doi:10.1016/0040-4020(80)80209-2

40. Normant, J. F.; Quirion, J. C.; Alexakis, A.; Masuda, Y. Tetrahedron Lett. 1989, 30, 3955. doi:10.1016/S0040-4039(00)99293-1

41. Kienle, M.; Unsinn, A.; Knochel, P. Angew. Chem. 2010, 122, 4860. doi:10.1002/ange.201001025 Angew. Chem. Int. Ed. 2010, 49, 4751. doi:10.1002/anie.201001025

42. Truce, W. E.; Simms, J. A. J. Am. Chem. Soc. 1956, 78, 2756. doi:10.1021/ja01593a029

\section{License and Terms}

This is an Open Access article under the terms of the Creative Commons Attribution License (http://creativecommons.org/licenses/by/2.0), which permits unrestricted use, distribution, and reproduction in any medium, provided the original work is properly cited.

The license is subject to the Beilstein Journal of Organic Chemistry terms and conditions: (http://www.beilstein-journals.org/bjoc)

The definitive version of this article is the electronic one which can be found at: $\underline{\text { doi: } 10.3762 / \text { bjoc } .8 .248}$ 